\title{
Effect of sodium ion coupled nutrient transport on intestinal permeability in chronically catheterised rats
}

\author{
M R Uhing
}

\begin{abstract}
Background-The significance of $\mathrm{Na}-$ nutrient cotransport induced alterations in paracellular permeability is controversial. Most previous studies have measured intestinal permeability using in vitro methods or in vivo methods immediately after surgical bowel manipulation, and therefore may not be applicable to normal physiological conditions.

Aims-To determine whether activation of Na coupled nutrient transport increases intestinal permeability under normal physiological conditions.

Methods-The effect of Na-nutrient cotransport on intestinal permeability was measured in unrestrained, unanaesthetised, chronically catheterised male Sprague-Dawley rats using two different methods: measurement of the rate of absorption of passively absorbed hexoses, mannitol and L-glucose; and measurement of the mannitol:urea diffusion ratio. Results-L-Glucose and mannitol absorption were not increased in the presence of D-glucose, alanine, maltose, or peptides. The mannitol:urea diffusion ratio was not increased by the presence of D-glucose. The presence of $D$-glucose in the intestinal lumen for 20 minutes did not alter intestinal permeability.

Conclusions-Under normal physiological conditions, Na coupled nutrient transport does not increase intestinal permeability.

(Gut 1998;43:22-28)
\end{abstract}

Keywords: intestinal permeability; tight junctions; paracellular absorption; Na-nutrient cotransport

The significance of Na-nutrient cotransport induced alterations in paracellular permeability is controversial. ${ }^{12}$ Although a series of studies has shown enhanced paracellular permeability with decreased transmucosal impedance and alterations in tight junction morphology, these studies were performed either in vitro or in vivo immediately following surgical manipulation of the intestines. ${ }^{3-8}$ We have previously shown that surgery significantly alters intestinal function, ${ }^{9}$ so the results from studies performed immediately after surgical manipulation of the intestine may not be applicable to normal physiological conditions.

In two recent studies, investigators eliminated the effects of surgery on intestinal function, and showed that Na-nutrient cotransport does not enhance paracellular permeability. ${ }^{10}{ }^{11}$ One study, conducted with a rat model, showed that the 24 hour urinary recovery of gavage infused inert sugars was not increased by the presence of D-glucose. ${ }^{10}$ However, several methodological limitations may have influenced these findings: (a) the hyperosmolar solution used to deliver glucose and inert sugars may have altered gastric permeability; (b) 24 hour urinary recovery of inert probes may have been too insensitive a measure to detect permeability changes occurring early in the experiment in the proximal small intestine where the D-glucose concentration was highest; (c) as D-glucose was absorbed in the proximal intestine whereas the inert probes progressed into the distal intestine, a significant amount of the inert probes may have been absorbed in the absence of $\mathrm{Na}$ cotransport, decreasing the ability to detect glucose induced changes in intestinal permeability.

The other study, conducted with a perfusion model in human subjects, showed that the diffusion ratios of mannitol:xylose and xylose: urea did not increase in the presence of D-glucose. ${ }^{11}$ However, constant perfusion of an intestinal segment with consequent luminal dilatation does not occur under normal physiological conditions, and has been shown to alter villus anatomy and subsequent physiological responses. ${ }^{12-15}$ Therefore, results from this research should be interpreted with awareness of this limitation.

In order to resolve the controversy over the significance of Na-nutrient cotransport induced alterations in paracellular permeability, experiments that maintain physiological intestinal conditions while controlling for the above methodological limitations are needed. Therefore, we examined the effect of $\mathrm{Na}$ coupled nutrient transport on intestinal permeability using a chronically catheterised rat model in which intestinal function is studied under normal physiological conditions, measuring the effect of $\mathrm{Na}$ coupled nutrient transport on the absorption rates of L-glucose and mannitol, and on the diffusion ratio of mannitol:urea.

\section{Methods}

ANIMALS

Male Sprague-Dawley rats weighing 240-400 g were obtained from Charles River Breeding Laboratories (Wilmington, Massachusetts, USA). The rats were maintained under a 10:14 hour light:dark cycle. Water and chow (Agway Rat Mouse Hamster Chow 3000) were available ad libitum except for four hours prior to
Accepted for publication 19 January 1998 
an experiment when the animals were fasted. This study was approved by the Institutional Animal Care and Use Committee.

The animals were anaesthetised with ketamine $60 \mathrm{mg} / \mathrm{kg}$ and xylazine $5.0 \mathrm{mg} / \mathrm{kg}$ intramuscularly. Catheters were placed in the aorta, portal vein, and duodenum under sterile conditions as previously described. ${ }^{16}$ To maintain catheter patency, the catheters were flushed daily with $0.35 \mathrm{ml}$ of $0.9 \% \mathrm{NaCl}$ containing 500 units $/ \mathrm{ml}$ of heparin and $2.5 \mathrm{mg} / \mathrm{ml}$ of ampicillin. Weights of the animals immediately prior to catheter placement and at four days postoperatively were 295 (42) and 286 (37) g, respectively.

\section{CHEMICALS}

All non-radioactive chemicals and reagents were obtained from Sigma Chemical Co. (St Louis, Missouri, USA). Radioactive isotopes were obtained from DuPont-New England Nuclear Research Products (Boston, Massachusetts, USA).

\section{EXPERIMENTAL DESIGN}

For all experiments, the following conditions were maintained. Measurements of intestinal absorption were performed at least four days postoperatively based on our previous findings that the effects of surgery had resolved and the animals had achieved at least $95 \%$ of their preoperative weight by this time. ${ }^{9}$ The animals were fasted for four hours prior to each experiment, and the osmolarity of the duodenal infusions standardised at 300 mosm by balancing the infusates with $\mathrm{NaCl}$. All duodenal infusions contained at least $50 \mathrm{mM}$ sodium which is above the $\mathrm{K}_{\mathrm{m}}$ of sodium for activation of $\mathrm{Na}$ coupled nutrient cotransport. ${ }^{17}$ When multiple experiments were performed in each animal, the experiments were separated by at least 24 hours. In paired experiments, the order of the infusates was assigned randomly.

\section{Effect of Na coupled nutrient transport on the absorption of L-glucose and mannitol}

The effect of Na coupled nutrient transport on the absorption rate of L-glucose and mannitol was studied in three separate groups of animals to test the effects of different activators of $\mathrm{Na}$ coupled transport. In the first group $(n=9)$, the absorption rate of $100 \mathrm{mM}$ L-glucose was measured alone and in the presence of each of the following: $100 \mathrm{mM}$ mannitol, $100 \mathrm{mM}$ D-glucose, $50 \mathrm{mM}$ maltose, and $50 \mathrm{mM}$ alanine. In the second group $(n=6)$, the absorption rate of $100 \mathrm{mM}$ L-glucose was measured alone and in the presence of each of the following: $50 \mathrm{mM}$ alanine, $50 \mathrm{mM}$ alanylproline, and $50 \mathrm{mM}$ alanylprolinylglycine. In the third group $(n=9)$, the absorption rate of $100 \mathrm{mM}$ mannitol was measured alone and in the presence of the following: $100 \mathrm{mM}$ L-glucose, $100 \mathrm{mM}$ D-glucose, and $50 \mathrm{mM}$ alanine.

In a subset of different animals, we tested the effect of more prolonged exposure to D-glucose on paracellular permeability. These animals served as their own controls for the infusion of either a D-glucose or L-glucose solution into the duodenum 10 minutes prior to the start of the mannitol infusion. The intestinal epithelium had thus been exposed to D-glucose or L-glucose for 11-14 minutes when measurement of mannitol absorption rates was started. The effect of prolonged exposure to D-glucose was studied using two different volumes and concentrations of D-glucose. For group A ( $\mathrm{n}=8), 0.5 \mathrm{ml}$ of a solution containing $100 \mathrm{mM}$ D-glucose was infused into the duodenum 10 minutes prior to the start of a 1 $\mathrm{ml}$ solution containing $100 \mathrm{mM}$ mannitol and $100 \mathrm{mM}$ D-glucose. For group B ( $\mathrm{n}=8), 1 \mathrm{ml}$ of $100 \mathrm{mM}$ D-glucose was infused into the duodenum 10 minutes prior to the start of a 1 $\mathrm{ml}$ solution of $100 \mathrm{mM}$ mannitol and $200 \mathrm{mM}$ D-glucose.

\section{Effect of Na coupled nutrient transport on the diffusion ratios of mannitol:urea and mannitol:tritiated water}

In these experiments, intestinal permeability was measured by calculating the diffusion ratio of two passively absorbed substances, mannitol and urea, at concentrations of $50 \mathrm{mM}$. Six animals (group A) served as their own controls for the measurement of mannitol:urea diffusion ratios in the presence of either $100 \mathrm{mM}$ D-glucose or $100 \mathrm{mM}$ L-glucose.

In separate experiments we studied the effect of a more prolonged exposure to D-glucose and L-glucose on the mannitol:urea diffusion ratio. With animals serving as their own controls, we infused varying volumes and concentrations of either D-glucose or L-glucose into the duodenum prior to measuring the mannitol:urea diffusion ratio for the following three groups of animals: group $B(n=6)$ received $0.5 \mathrm{ml}$ of 100 $\mathrm{mM}$ D-glucose 10 minutes prior to the mannitol-urea solution; group $C(n=5)$ received $1.0 \mathrm{ml}$ of $200 \mathrm{mM}$ D-glucose 10 minutes prior to the mannitol-urea solution; and group $\mathrm{D}(\mathrm{n}=7)$ received $2 \mathrm{ml}$ of $100 \mathrm{mM}$-glucose as a constant infusion $(0.1 \mathrm{ml} / \mathrm{min})$ beginning 20 minutes prior to the mannitol-urea solution.

MEASUREMENT OF L-GLUCOSE AND MANNITOL ABSORPTION RATES

The absorption rates of L-glucose and mannitol were measured by the previously described dual infusion method, a measure of transepithelial absorption. ${ }^{9}$ Using this method, the absorption rate of a substance is determined from the rate at which it appears in the blood from the intestinal lumen.

In this study, the dual infusion method for measuring L-glucose and mannitol absorption was performed in the following manner. Tracer amounts of ${ }^{14} \mathrm{C}$ L-glucose or ${ }^{14} \mathrm{C}$ mannitol $(0.4$ $\mu \mathrm{Ci} / \mathrm{ml})$ in $0.9 \% \mathrm{NaCl}$ were infused continuously into the portal vein at $0.2 \mathrm{ml} / \mathrm{min}$. Simultaneously, a $1.0 \mathrm{ml}$ bolus of L-glucose or mannitol with tracer amounts of the ${ }^{3} \mathrm{H}$ isotopes (8 $\mu \mathrm{Ci} / \mathrm{ml}$ ) was infused into the duodenum. After approximately one minute, six serial aortic blood samples $(0.25 \mathrm{ml}$ each $)$ were withdrawn from the aortic catheter. The slope of the ${ }^{3} \mathrm{H}$ and ${ }^{14} \mathrm{C}$ concentrations in the blood versus time were determined by linear regression analysis. The uptake of ${ }^{3} \mathrm{H}$ was determined as follows: 


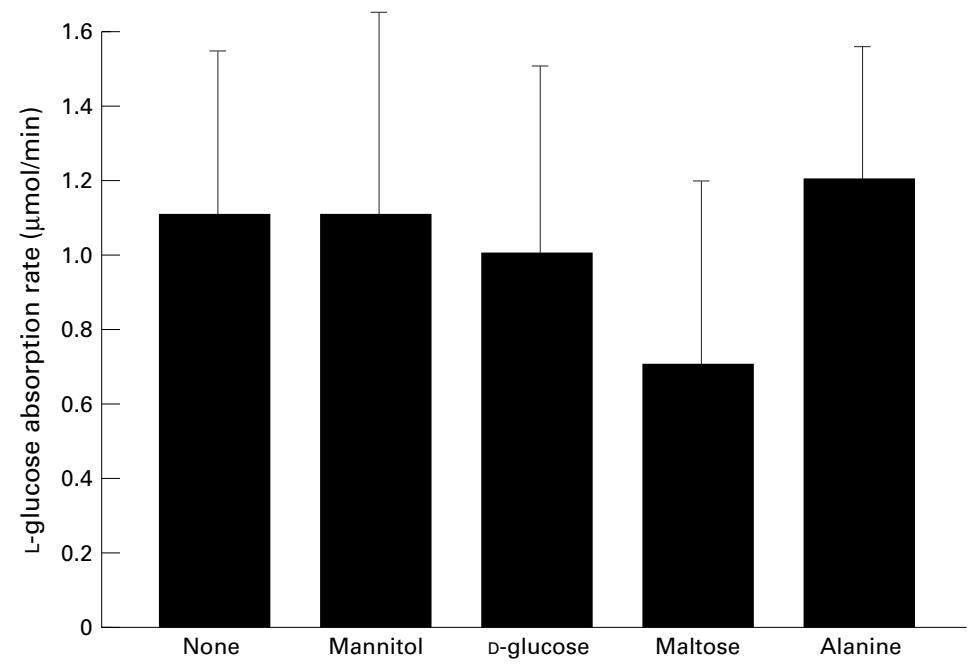

Figure 1 Effect of $\mathrm{Na}$ coupled transport on the absorption rate of $L$-glucose. Bars represent mean $(S D) ; n=9$.

$$
\begin{aligned}
& \begin{array}{l}
\text { Uptake of }{ }^{3} \mathrm{H}= \\
\text { (slope of }{ }^{3} \mathrm{H} \text { ) (infusion rate of }{ }^{14} \mathrm{C} \text { ) }
\end{array} \\
& \text { (slope of }{ }^{14} \mathrm{C} \text { ) }
\end{aligned}
$$

The uptake of ${ }^{3} \mathrm{H}$ was divided by the specific activity of ${ }^{3} \mathrm{H}$ in the infusate to determine the rate of uptake for each hexose.

\section{MEASUREMENT OF DIFFUSION RATIOS}

Potential changes in intestinal permeability were identified by comparing the diffusion ratios of different sized, passively absorbed solutes. These comparisons were based on the principle of restricted diffusion in which an increase in membrane permeability is indicated by an increase in the relative diffusion of a large versus a small solute. ${ }^{11} 1819$

We have previously described the use of portal venous-aortic concentration gradients (PV-A) for comparing L-glucose and 3-Omethylglucose absorption rates. ${ }^{16}$ In this study, we used a similar method to describe the effect of D-glucose on the relative permeability of three passively absorbed solutes: tritiated water (THO, molecular weight $(\mathrm{MW})=18)$, urea

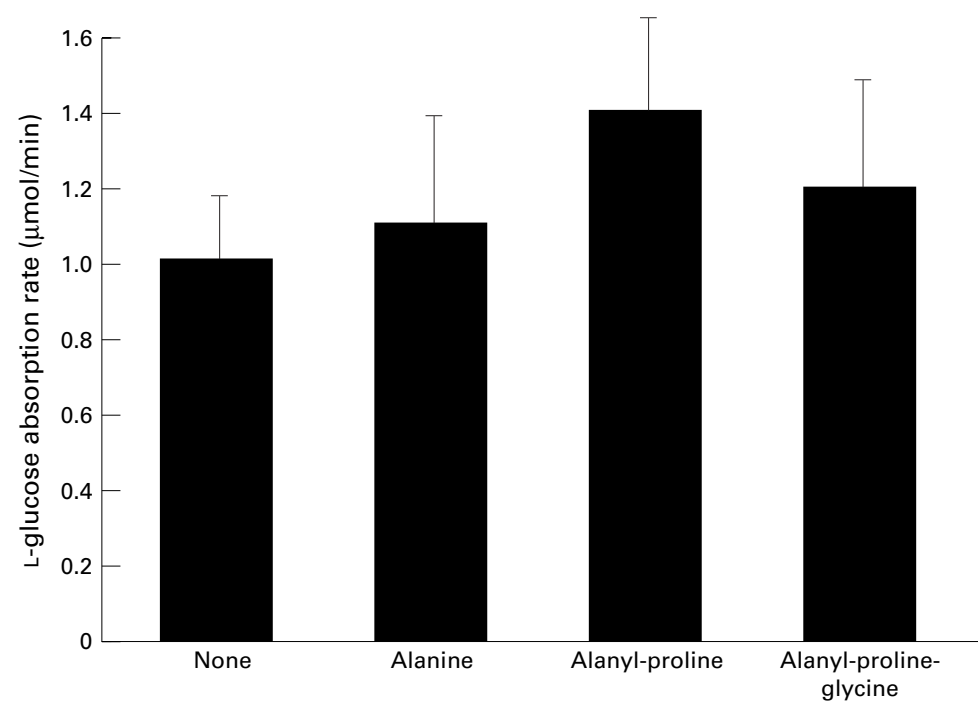

Figure 2 Effect of alanine and peptides on the rate of L-glucose absorption. Bars represent mean $(S D) ; n=6$.
$(\mathrm{MW}=60)$, and mannitol $(\mathrm{MW}=180)$. The diffusion ratios of mannitol:urea and mannitol:THO were determined from the PV-As of each molecule after its infusion into the duodenum in the presence or absence of $100 \mathrm{mM}$ D-glucose.

In this study, the diffusion ratios of mannitol:urea and mannitol:THO were determined in the following manner. A $1.0 \mathrm{ml}$ bolus of a solution containing one of the following two combinations of diffusion probes was infused over 0.6 minutes: (a) $50 \mathrm{mM}$ urea and $50 \mathrm{mM}$ mannitol with tracer amounts of ${ }^{14} \mathrm{C}$ urea $(0.5$ $\mu \mathrm{Ci} / \mathrm{ml})$ and ${ }^{3} \mathrm{H}$ mannitol $(2.0 \mu \mathrm{Ci} / \mathrm{ml})$; or $(b)$ $50 \mathrm{mM}$ mannitol with tracer amounts of ${ }^{14} \mathrm{C}$ mannitol $(2.3 \mu \mathrm{Ci} / \mathrm{ml})$ and tritiated water (1 $\mu \mathrm{Ci} / \mathrm{ml}$ ). From 1 to 2.5 minutes after the start of the duodenal infusion, three simultaneous serial blood samples $(0.25 \mathrm{ml}$ each $)$ were withdrawn from the aortic and portal venous catheters. The diffusion ratio was determined in the presence of both $100 \mathrm{mM}$ D-glucose and 100 $\mathrm{mM}$ L-glucose, as described previously.

The diffusion ratio was calculated from the PV-A of the probes according to the following principles. The absorption rate $(\mathrm{J})$ of any substance across the intestine is equal to the concentration difference of the substance in the blood entering and exiting the intestine multiplied by the rate of blood flow through the intestine:

$$
\mathrm{J}=(\mathrm{PV}-\mathrm{A}) \times \text { flow }
$$

For two passively absorbed substances, a and $b$, the diffusion ratio (DR) of substance $a: b$ is calculated as follows:

$\mathrm{DR}_{\mathrm{a} / \mathrm{b}}=\left(\mathrm{J}_{\mathrm{a}} / \Delta \mathrm{C}_{\mathrm{a}}\right) /\left(\mathrm{J}_{\mathrm{b}} / \Delta \mathrm{C}_{\mathrm{b}}\right)$

where $\Delta \mathrm{C}$ is the concentration gradient from the intestinal lumen to the blood. Equation (2) is substituted into equation (3):

$$
\mathrm{DR}_{\mathrm{a} / \mathrm{b}}=\frac{\left([\mathrm{PV}-\mathrm{A}]_{\mathrm{a}} \times \text { flow } / \Delta \mathrm{C}_{\mathrm{a}}\right)}{\left([\mathrm{PV}-\mathrm{A}]_{\mathrm{b}} \times \text { flow } / \Delta \mathrm{C}_{\mathrm{b}}\right)}
$$

If flow is the same for measurements of both $[\mathrm{PV}-\mathrm{A}]_{\mathrm{a}}$ and $[\mathrm{PV}-\mathrm{A}]_{\mathrm{b}}$ as is automatically true by our method in which both are measured simultaneously, then equation (4) simplifies to:

$\mathrm{DR}_{\mathrm{a} / \mathrm{b}}=\left([\mathrm{PV}-\mathrm{A}]_{\mathrm{a}} / \Delta \mathrm{C}_{\mathrm{a}}\right) /\left([\mathrm{PV}-\mathrm{A}]_{\mathrm{b}} / \Delta \mathrm{C}_{\mathrm{b}}\right)$

By convention, the diffusion ratio is expressed as the ratio of the less to the more permeable molecule, so is always less than 1 .

In previous experiments we found that a 1.0 $\mathrm{ml}$ duodenal infusion was diluted $15 \%$ by luminal contents, ${ }^{9}$ so for this study $\Delta \mathrm{C}$ was calculated using the knowledge that the luminal concentration of a substance was $85 \%$ of the concentration infused. Mannitol is not normally present in blood, so the blood concentration for $\Delta \mathrm{C}$ was calculated from the aortic blood concentration used to calculate PV-A. Urea is normally present in the blood of rats, so we calculated $\Delta \mathrm{C}$ based on previous findings that the blood urea concentration was 6 $\mathrm{mM}^{20}{ }^{21}$ For THO, $\Delta \mathrm{C}$ was calculated for THO only and not for total water concentration. Since each animal served as its own control, any interanimal variability in the blood concentrations of $\mathrm{THO}$ and urea would have little effect on the measurement of glucose induced changes in the diffusion ratio. 


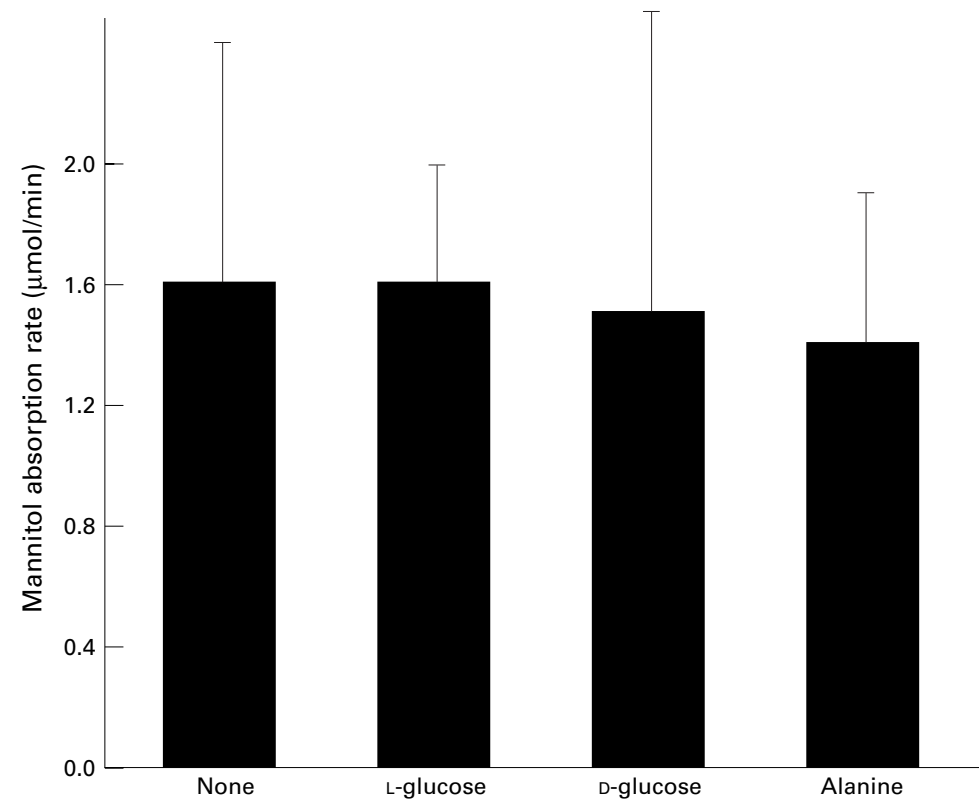

Figure 3 Effect of $\mathrm{Na}$ coupled transport on the absorption rate of mannitol. Bars represent mean (SD); $n=9$.
ANALYTICAL METHODS

Blood samples $(0.25 \mathrm{ml})$ were added to $0.3 \mathrm{ml}$ of $1.0 \mathrm{M} \mathrm{HClO}_{4}$ and centrifuged for 5 minutes at $17000 \mathrm{rpm}$ in a Microfuge E (Beckman Instruments, Palo Alto, California, USA). Weights were obtained on the blood sample tubes at three time points: empty, after the addition of $\mathrm{HClO}_{4}$, and after the addition of the blood sample, in order to quantitate the volume of sample dilution due to $\mathrm{HClO}_{4}$. Then, duplicate $0.1 \mathrm{ml}$ aliquots of the supernatant were counted in $5 \mathrm{ml}$ of scintillation fluid (EcoLume, ICN, Costa Mesa, California, USA). The radioactivity was measured in a Mark V scintillation counter (Model 5303). The windows in the scintillation counter were adjusted so that all of the ${ }^{3} \mathrm{H}$ was in a single channel. The amount of crossover of ${ }^{14} \mathrm{C}$ into this channel was then calculated using standards.

\section{STATISTICAL ANALYSIS}

Analysis of variance for repeated measures was used to detect the effect of $\mathrm{Na}$ coupled nutrient transport on the absolute absorption rates of mannitol and L-glucose. This statistic controls for the within animal effect of the rats serving as their own controls for different infusates. Two tailed paired $t$ tests were used for comparisons which tested the effects of D-glucose on mean diffusion ratios. For all statistics, values are expressed as mean (SD), and the alpha error was set at 0.05 . increase intestinal permeability acutely ${ }^{22}$ so mannitol:urea diffusion ratio would be expected to increase following oleic acid infusion. In three of the rats, we continuously infused 2 $\mathrm{ml}$ of $64 \mathrm{mM}$ oleic acid starting 20 minutes prior to infusion of the solution containing mannitol and urea. The mannitol:urea diffusion ratios before and after the infusion of 64 $\mathrm{mM}$ oleic acid were $0.11(0.1)$ and $0.33(0.2)$, respectively, indicating that the diffusion ratio of mannitol:urea was a sensitive indicator of increased intestinal permeability over the time frame of our experiments.

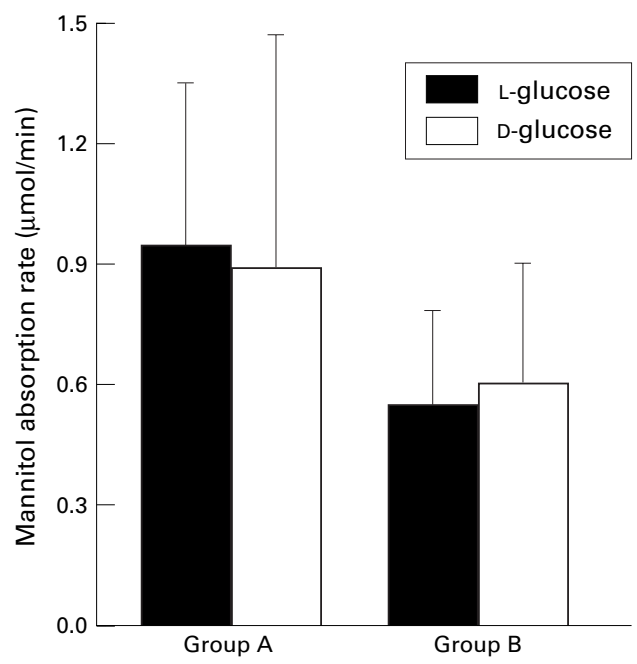

Figure 4 Effect of infusing luminal glucose 10 minutes prior to measuring the rate of mannitol absorption at a concentration of $100 \mathrm{mM}$. Group $A, n=8$; group $B, n=8$. Bars represent mean (SD).

\section{Results}

EFFECT OF Na COUPLED NUTRIENT TRANSPORT ON THE ABSORPTION OF L-GLUCOSE AND MANNITOL

No significant differences were found in the absorption rates of $\mathrm{L}$-glucose in the presence of $100 \mathrm{mM}$ mannitol, $100 \mathrm{mM}$ D-glucose, $50 \mathrm{mM}$ maltose, $50 \mathrm{mM}$ alanine, $50 \mathrm{mM}$ alanylproline, or $50 \mathrm{mM}$ alanylprolinylglycine (figs 1 and 2). We also found that mannitol absorption was not altered by the presence of $100 \mathrm{mM}$ L-glucose, $100 \mathrm{mM}$ D-glucose, or $50 \mathrm{mM}$ alanine (fig 3).

The presence of D-glucose in the intestinal lumen for 10 minutes did not increase the mannitol absorption rate for either group $\mathrm{A}$ (0.5 ml of $100 \mathrm{mM}$ D-glucose) or group B (1.0 $\mathrm{ml}$ of $200 \mathrm{mM}$ D-glucose) when compared with the mannitol absorption rate for solutions containing L-glucose (fig 4). The mean mannitol absorption rates were lower in these experiments when compared with values depicted in fig 3, because for experiments in fig 4 , the luminal mannitol concentration was diluted by the preinfusion of glucose solutions.

EFFECT OF Na COUPLED NUTRIENT TRANSPORT ON THE DIFFUSION RATIOS OF MANNITOL:UREA AND MANNITOL:THO

The mannitol:urea diffusion ratio was not significantly different in the presence of D-glucose versus L-glucose for group A $(\mathrm{p}=0.99)$, group $\mathrm{B}(\mathrm{p}=0.29)$, group $\mathrm{C}$ $(\mathrm{p}=0.18)$, or group $\mathrm{D}(\mathrm{p}=0.94)$, indicating that intestinal permeability did not increase as 


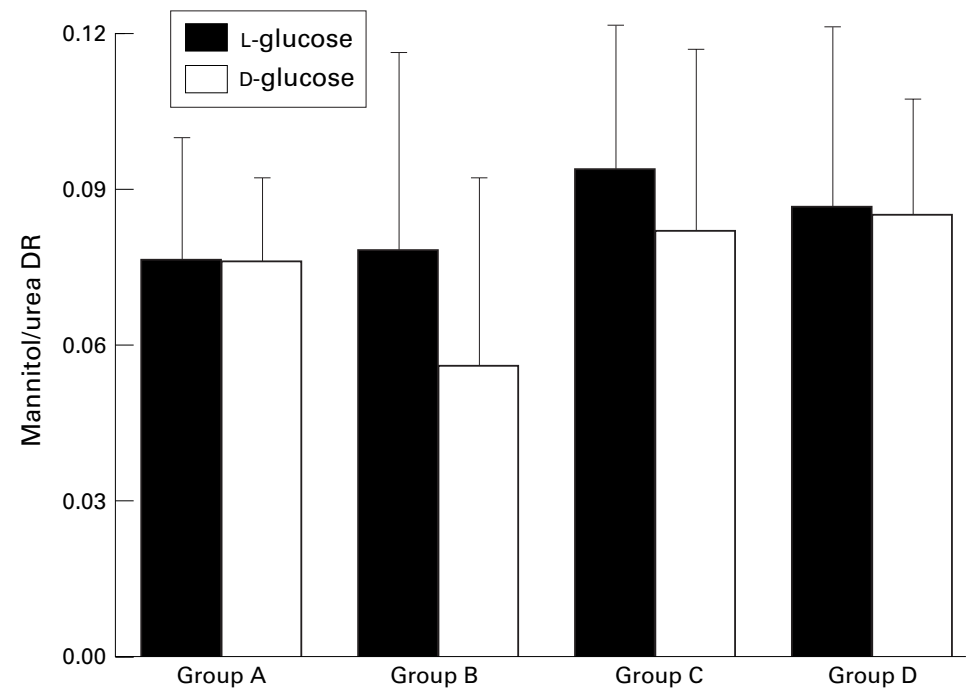

Figure 5 The effect of D-glucose on the diffusion ratio (DR) of mannitol:urea. Bars represent mean (SD). a result of $\mathrm{D}$-glucose in the intestinal lumen for up to 20 minutes (fig 5).

Data from the four groups were combined to compare the effects of D-glucose and L-glucose on mean PV-A for mannitol and urea. The results revealed that in the presence of D-glucose versus L-glucose, the gradients were higher for both mannitol $(18.5 \mathrm{nmol} / \mathrm{ml}$ versus $17.1 \mathrm{nmol} / \mathrm{ml})$ and urea $(250.5 \mathrm{nmol} / \mathrm{ml}$ versus $192.6 \mathrm{nmol} / \mathrm{ml})$. These differences reflect a solvent drag effect from increased water absorption, and because both mannitol and urea were affected equally, the diffusion ratio was unchanged.

We found that the diffusion ratio of mannitol (nmoles)/THO $(\mu \mathrm{mol})$ was significantly lower in the presence of D-glucose than for controls (fig $6, \mathrm{p}=0.002$ ). This was due to an increase in the PV-A gradient of THO in the presence of D-glucose $(1210 \mu \mathrm{mol} / \mathrm{ml})$ versus controls $(779$ $\mu \mathrm{mol} / \mathrm{ml}) \quad(\mathrm{p}=0.047)$. Thus, D-glucose increased the rate of water absorption more than the rate of mannitol absorption.

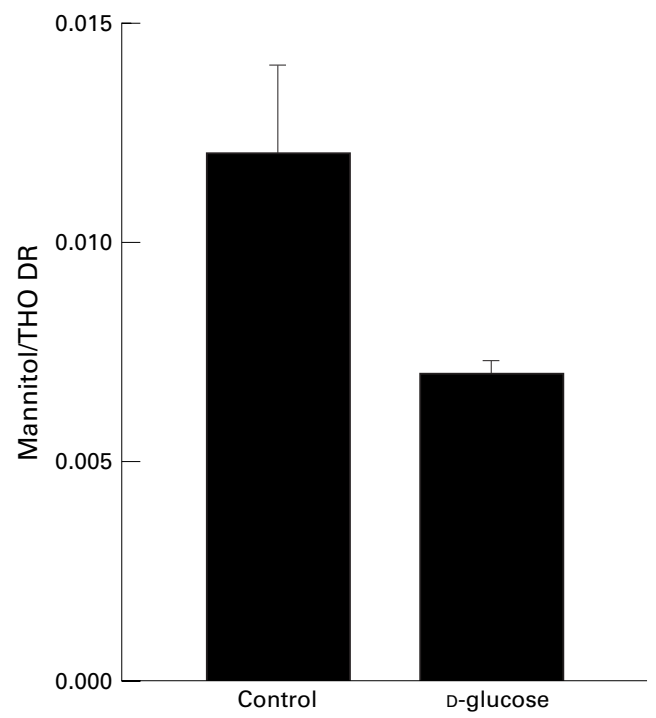

Figure 6 Effect of $D$-glucose on the diffusion ratio (DR) of mannitol:THO $(n=6)$.

\section{Discussion}

The results of this study indicate that activation of $\mathrm{Na}$ nutrient cotransport does not alter intestinal permeability under normal physiological conditions. This conclusion was based on the following findings: the absorption rates of mannitol and L-glucose were not increased by D-glucose, alanine, maltose, alanylproline, or alanylprolinylglycine; and the mannitol:urea diffusion ratio was not increased by the presence of D-glucose in the intestinal lumen for as long as 20 minutes. These findings also do not support previous hypotheses that tight junction permeability is increased by the high concentration of $\mathrm{Na}$ cotransported monomers that result from enzyme induced hydrolysis of peptides and polysaccharides at the epithelial membrane.

The inconsistency between our findings and those of other investigators probably reflect methodological differences in that our experimental methods controlled for the limitations that characterised previous research. In our study, intestinal function was studied under normal physiological conditions without the influence of surgery. The animals were unrestrained, non-stressed, and gaining weight. The intestine was not perfused at a constant flow rate, avoiding the occurrence of persistent luminal distension which potentially alters intestinal function. Instead, the isoosmolar duodenal infusions were given as a bolus infusion so that the Na coupled transport activators and the diffusion probes were present in the intestinal lumen at the same time. The absorption rates and diffusion ratios of probes were measured by blood levels, so that transport rates reflect transepithelial absorption. In addition, measuring blood levels of probes may be more sensitive to small changes in intestinal permeability compared with 24 hour urinary recovery studies.

Although our chronically catheterised rat model does not permit determination of either the exact concentration of solutes in the intestinal lumen or the length of intestine perfused, we addressed this limitation by measuring the mannitol:urea diffusion ratio. When the diffusion of the two solutes is measured simultaneously and expressed as a ratio, the effect of variables such as motility, luminal dilution, and surface area are eliminated..$^{18}$ In addition, the diffusion ratios of solutes that are passively absorbed through a membrane are not affected by the direction and rate of water flow through the membrane. ${ }^{18} 19$

Our choice of L-glucose, mannitol, and urea to serve as probes of intestinal permeability is consistent with that of previous investigators, who used these or smaller probes. ${ }^{3} 101123-27$ L-Glucose, mannitol, and urea are inert and passively absorbed through paracellular channels, and mannitol and L-glucose are similar in size to amino acids and other hexoses for which paracellular absorption has been hypothesised to be significant. ${ }^{1127-29}$

The results of our study are consistent with those of previous investigators who measured intestinal permeability in vivo without the influence of surgical bowel manipulation. ${ }^{10}{ }^{11}$ 
Using a perfusion method, Fine et al found that D-glucose did not increase either the mannitol absorption rate or the diffusion ratios of mannitol:xylose and xylose:urea. ${ }^{11}$ Similarly, Schwartz et al showed that D-glucose did not increase the total absorption of L-glucose, L-galactose, L-mannose, or D-mannitol, and that the fraction of D-glucose absorption occurring by paracellular transport was minimal. ${ }^{10}$ Furthermore, our current findings are consistent with our previous work in which we showed no effect on the L-glucose (PV-A) gradient by luminal 3-O-methylglucose, a D-glucose analogue that uses the same transport mechanisms as D-glucose. ${ }^{16}$

The results of this study differ from those from previous in vivo and in vitro research in which the intestine had been surgically manipulated..$^{3-8}$ These differences suggest that the surgical procedure and its accompanying sequelae may have influenced the findings from these previous studies. This speculation is consistent with the research in this area: (1) surgery and anaesthesia decrease intestinal blood flow which may alter absorption of nutrients and drugs ${ }^{30-32} ;(2)$ restraint of an animal causes a stress induced increase in intestinal permeability, as measured by mannitol absorption ${ }^{33}$; and (3) surgical bowel manipulation results in an $86 \%$ decrease in the active transport of glucose. ${ }^{9}$

Furthermore, low cellular energy levels secondary to lack of oxygen or lack of metabolic substrates may explain the findings of previous studies which showed increased intestinal permeability secondary to $\mathrm{Na}$ cotransport. Using an acute perfusion model, Nicholls et al showed that most luminal glucose was metabolised to lactate in the intestine, ${ }^{34}$ whereas in a chronically catheterised rat model, Rich-Denson and Kimura showed that almost all luminal glucose was absorbed intact and not metabolised to lactate by the intestine. ${ }^{35}$ The results of Nicholls et al were replicated in the chronically catheterised rats only when the animals were placed in a hypoxic environment $\left(\mathrm{FIO}_{2}\right.$ of 0.07$)$, indicating that in the experiments of Nicholls et al, cellular energy levels were probably low despite normal blood oxygen levels. In related research on the effect of low cellular energy levels on epithelial function, Mandel et al showed that energy depletion of kidney epithelial cells altered tight junction structure and increased tight junction permeability without affecting epithelial membrane integrity. ${ }^{36}$

Similarly, our findings that exposing the intestine to glucose for 10 to 20 minutes did not increase either the mannitol absorption rate or the mannitol:urea diffusion ratio differ from those of investigators whose studies involved in vitro methods and intestinal surgery. Atisook and colleagues ${ }^{3}$ and Pappenheimer ${ }^{6}$ found that the effect of $\mathrm{Na}$ nutrient cotransport on enhanced permeability was maximal at 10 minutes. These findings may reflect the postsurgical condition of the intestine, in which the higher unstirred water layer delays the diffusion of solutes from the bulk phase of the luminal fluid to the microvil- lus membrane for activation of the $\mathrm{Na}$ cotransporter. $^{937}$ Our previous research has shown that active transport of glucose is ninefold higher when the adverse effects of surgery are eliminated. ${ }^{9}$ Thus, using our model in which the intestine was functioning maximally, any $\mathrm{Na}$ coupled transport induced effect on intestinal permeability should have occurred earlier than the 10 minutes described by Atisook et al and Pappenheimer.

Two major lines of evidence have been used to support the theory that activation of $\mathrm{Na}$ nutrient cotransport increases paracellular permeability. The first is that $\mathrm{Na}$ nutrient cotransport increases transmucosal impedance with dilatation of lateral spaces and alterations in tight junction morphology. ${ }^{3-68}$ In these studies, increased intestinal permeability could be elicited only when the intestine was deprived of glucose for 15 minutes prior to the experiments, leading Pappenheimer and Atisook et al to hypothesise that intestinal tissue stores of glucose must be entirely depleted before tight junction permeability could be increased by D-glucose. ${ }^{368}$ These investigators have suggested that in in vivo models, despite the absence of luminal glucose, a constant supply of 3-5 $\mathrm{mM}$ glucose from the plasma is sufficient to activate $\mathrm{Na}$ cotransport leading to an increase in permeability. ${ }^{38}$ In order to survive animals must maintain a constant plasma glucose concentration precluding the complete depletion of intestinal glucose stores, so the findings of these studies cannot be applied to normal physiological conditions.

The other line of evidence supporting the theory that $\mathrm{Na}$ coupled nutrient transport increases paracellular permeability is that under normal conditions animals ingest and absorb glucose in quantities that exceed the apparent transport capacity of the entire intestine. ${ }^{24} 27$ These speculations are based on estimates of maximum transport rates $\left(J_{\max }\right)$ obtained from in vitro methods. Although these investigators have assumed that in vitro measures of glucose and amino acid transport accurately reflect nutrient absorption rates under normal physiological conditions, our previous work has not supported this assumption. We showed that surgical bowel manipulation decreases active transport of glucose by $86 \%$, and using our estimates of $\mathrm{J}_{\max }$ for glucose, no discrepancy between ingestion rates and intestinal transport capacity exists. ${ }^{9}$

Our findings that tight junction permeability did not increase in response to $\mathrm{Na}$ coupled nutrient transport are consistent with the results of previous in vivo studies that have been criticised because of inadequate fluid absorption during the experiments. ${ }^{1}$ In our animals, we found that the PV-As of THO were $779 \mu \mathrm{mol}$ and $1210 \mu \mathrm{mol}$ in the absence and presence of D-glucose, respectively. Portal venous blood flow in rats is $10-12 \mathrm{ml} / \mathrm{min} / 100$ g body weight, ${ }^{31}$ so for animals in this study, mucosal to serosal absorption of THO was $0.42-0.65 \mathrm{ml} / \mathrm{min}$ (equation 2). These figures correspond to a mucosal to serosal THO absorption rate equivalent of $1.5-2.3 \mathrm{ml} / \mathrm{cm} / \mathrm{h}$, based on our previous data showing that a $1 \mathrm{ml}$ 
infusion into the duodenum in our rats perfused $16.8 \mathrm{~cm}$ of intestine. ${ }^{9}$ Net water absorption could not be calculated because serosal to mucosal water flow could not be determined. These data are comparable to water absorption rates in other in vivo studies. ${ }^{11}$ Most important, however, is the fact that our findings reflect the effect of Na-nutrient transport under water absorption rates that would occur under normal physiological conditions. On the other hand, if Na-nutrient cotransport induced alterations in intestinal permeability can be detected only at supraphysiological rates of water absorption, then the physiological significance of any change in permeability is probably very small.

In summary, the results of this study show that under normal physiological conditions, the activation of Na-nutrient cotransport by glucose or amino acids does not significantly increase intestinal permeability. In a recent paper, Turner and Madara ${ }^{1}$ reviewed the studies addressing the Na-nutrient cotransport induced changes in tight junction permeability, and delineated potential reasons for the differing results. Although this review did not address the conditions under which the various studies were performed, this factor appears to be inextricably linked to the differing results. In vivo studies performed under normal physiological conditions have not shown significant Na-nutrient cotransport induced changes in intestinal permeability, and have revealed that only a small amount of glucose and amino acid absorption occurs by paracellular transport. ${ }^{1016}$ In contrast, those studies suggesting a significant alteration in intestinal permeability secondary to $\mathrm{Na}$ coupled transport were conducted using unphysiological in vitro or in vivo methods. The results of in vivo studies showing an apparent discrepancy between intestinal transport capacity and the ability of animals to ingest nutrients were compromised by the fact that the investigators based their comparisons on glucose and amino acid transport rates obtained from in vitro studies. ${ }^{24} 27$ Therefore, while $\mathrm{Na}$ coupled nutrient transport may increase tight junction permeability under extreme experimental conditions, alterations in intestinal permeability due to $\mathrm{Na}$ nutrient cotransport do not seem to be physiologically significant.

1 Turner JR, Madara JL. Physiological regulation of intestinal epithelial tight junctions as a consequence of $\mathrm{Na}(+)$ epithelial tight junctions as a consequence of $\mathrm{Na}(+)-$
coupled nutrient transport. Gastroenterology

2 Pappenheimer JR. On the coupling of membrane digestion with intestinal absorption of sugars and amino acids. $A m \mathcal{F}$ Physiol 1993;265:G409-17.

3 Atisook K, Carlson S, Madara JL. Effects of phlorizin and sodium on glucose-elicited alterations of cell junctions in intestinal epithelia. Am f Physiol 1990;258:C77-85.

4 Atisook K, Madara JL. An oligopeptide permeates intestinal tight junctions at glucose-elicited dilatations. Implications for oligopeptide absorption. Gastroenterology 1991;100: 719-24.

5 Madara JL, Pappenheimer JR. Structural basis for physiological regulation of paracellular pathways in intestinal epithelia. F Membr Biol 1987;100:149-64.

6 Pappenheimer JR. Physiological regulation of transepithelial impedance in the intestinal mucosa of rats and hamsters. $\mathcal{F}$ Membr Biol 1987;100:137-48.

7 Pappenheimer JR. Physiological regulation of epithelial junctions in intestinal epithelia. Acta Physiol Scand Suppl 1988;571:43-51.
8 Pappenheimer JR, Volpp K. Transmucosal impedance of mall intestine: correlation with transport of sugars and amino acids. Am f Physiol 1992;263:C480-93.

9 Uhing MR, Kimura RE. The effect of surgical bowel manipulation and anesthesia on intestinal glucose absorption in rats. $\mathcal{F}$ Clin Invest 1995;95:2790-8.

10 Schwartz RM, Furne JK, Levitt MD. Paracellular intestinal transport of six-carbon sugars is negligible in the rat. Gastroenterology 1995;109:1206-13.

11 Fine KD, Santa AC, Porter JL, et al. Effect of D-glucose on intestinal permeability and its passive absorption in human
small intestine in vivo. Gastroenterology 1993;105:1117-25.

12 Hakim AA, Lifson N. Effects of pressure on water and solute transport by dog intestinal mucosa in vitro. Am $\mathcal{F}$ Physiol 1969;216:276-84

13 Harris MS, Kennedy JG. Relationship between distention and absorption in rat intestine. II. Effects of volume and flow rate on transport. Gastroenterology 1988;94:1172-9.

14 Karbach U, Wanitschke R. Influence of serosal hydrostatic pressure on net water and electrolyte transport across the isolated rat colonic mucosa exposed to different secretagogues. Naunyn Schmiedebergs Arch Pharmacol 1984;327:33641

15 Lee JS. Intraluminal distension pressure on intestinal lymph flow, serosal transudation and fluid transport in the rat. $\mathcal{F}$ Physiol Lond 1984;355:399-409.

16 Uhing MR, Kimura RE. Active transport of 3-O-methylglucose by the small intestine in chronically catheterized glucose by the small intestine in chr
rats. $\mathcal{F}$ Clin Invest 1995;95:2799-805.

17 Hopfer U. Kinetics of $\mathrm{Na}$ +-dependent D-glucose transport. f Supramol Struct 1977;7:1-13

18 Renkin EM. Filtration, diffusion, and molecular sieving through porous cellulose membranes. f Gen Physiol 1954;38:225-43.

19 Fordtran JS, Rector FC, Locklear TW, et al. Water and solute movement in the small intestine of patients with sprue. f Clin Invest 1967;46:287-98.

20 Silver SM, DeSimone JA Jr, Smith DA, et al. Dialysis disequilibrium syndrome (DDS) in the rat: role of the "reverse urea effect". Kidney Int 1992;42:161-6.

21 Adams KE, Brown PA, Heys SD, et al. Alleviation of experimental cyclosporin A nephrotoxicity by low dose aspirin in the rat. Biochem Pharmacol 1993;46:2104-8.

22 Velasquez OR, Henninger $\mathrm{K}$, Fowler $\mathrm{M}$, et al. Oleic acid-induced mucosal injury in developing piglet intestine. Am F Physiol 1993;264:G576-82.

23 Krugliak P, Hollander D, Schlaepfer CC, et al. Mechanisms and sites of mannitol permeability of small and large intestine in the rat. Dig Dis Sci 1994;39:796-801.

24 Pappenheimer JR. Paracellular intestinal absorption of glucose, creatinine, and mannitol in normal animals: relation to body size. Am f Physiol 1990;259:G290-9

25 Madara JL, Barenberg D, Carlson S. Effects of cytochalasin $\mathrm{D}$ on occluding junctions of intestinal absorptive cells: further evidence that the cytoskeleton may influence paracellular permeability and junctional charge selectivity. $f$ Cell Biol 1983;97:125-36.

26 Madara JL, Moore R, Carlson S. Alteration of intestinal tight junction structure and permeability by cytoskeleton contraction. Am F Physiol 1987;253:C854-61.

27 Karasov WH, Cork SJ. Glucose absorption by a nectarivorous bird: the passive pathway is paramount. Am F Physiol 1994;267:G18-26.

28 Ochsenfahrt $\mathrm{H}$, Winne $\mathrm{D}$. The contribution of solvent drag to the intestinal absorption of tritiated water and urea from the jejunum of the rat. Naunyn Schmiedebergs Arch Pharmacol 1973;279:133-52.

29 Meddings JB, Westergaard H. Intestinal glucose transport using perfused rat jejunum in vivo: model analysis and derivation of corrected kinetic constants. Clin Sci 1989;76: 403-13.

30 Colombato LA, Sabba C, Polio J, et al. Influence of anesthesia, postanesthetic state, and restraint on superior mesenteric arterial flow in normal rats. Am $\mathcal{f}$ Physiol 1991;260:G1-6.

31 Gumbleton M, Nicholls PJ, Taylor G. Differential influence of laboratory anaesthetic regimens upon renal and hepatosplanchnic haemodynamics in the rat. 7 Pharm Pharmacol 1990;42:693-7.

32 Winne D. Influence of blood flow on intestinal absorption of drugs and nutrients. Pharmacol Ther 1979;6:333-93.

33 Saunders PR, Kosecka U, McKay DM, et al. Acute stressors stimulate ion secretion and increase epithelial permeability in rat intestine. Am f Physiol 1994;267:G794-9.

34 Nicholls TJ, Leese HJ, Bronk JR. Transport and metabolism of glucose by rat small intestine. Biochem $\mathcal{f} 1983 ; 212: 183-$ 7.

35 Rich-Denson C, Kimura RE. In vivo evidence that most of the intraluminally absorbed glucose is absorbed intact into the portal vein and not metabolized to lactate. Biochem $\mathcal{F}$ 1988;254:931-4

36 Mandel LJ, Bacallao R, Zampighi G. Uncoupling of the molecular "fence" and paracellular "gate" function in epithelial tight junctions. Nature 1993;361:552-5.

37 Anderson BW, Levine AS, Levitt DG, et al. Physiological measurement of luminal stirring in perfused rat jejunum. Am F Physiol 1988;254:G843-8.

38 Pappenheimer JR, Reiss KZ. Contribution of solvent drag through intercellular junctions to absorption of nutrients by the small intestine of the rat. 7 Membr Biol 1987;100: 123-36. 